\title{
Is it now time to remove that question mark?
}

\author{
Quan- Hoang Vuong
}

December 1, 2021

Ten years ago, around 2011, when we wrote down the first words of the paper titled "Serendipity as a strategic advantage?" we thought of the whole title as a single term, a single idea. The question mark was used to indicate that the whole idea is somewhat hypothetical. (Initially, we used "competitive" instead of "strategic".)

As an emerging research topic, serendipity has now been attracting many scholars from different walks of life. Consequently, the paper-later published by Praeger as a contributed chapter in Wilkinson's volume in 2013 [1]-has received many citations from, inter alia, journal articles, books, conference papers, and dissertations.

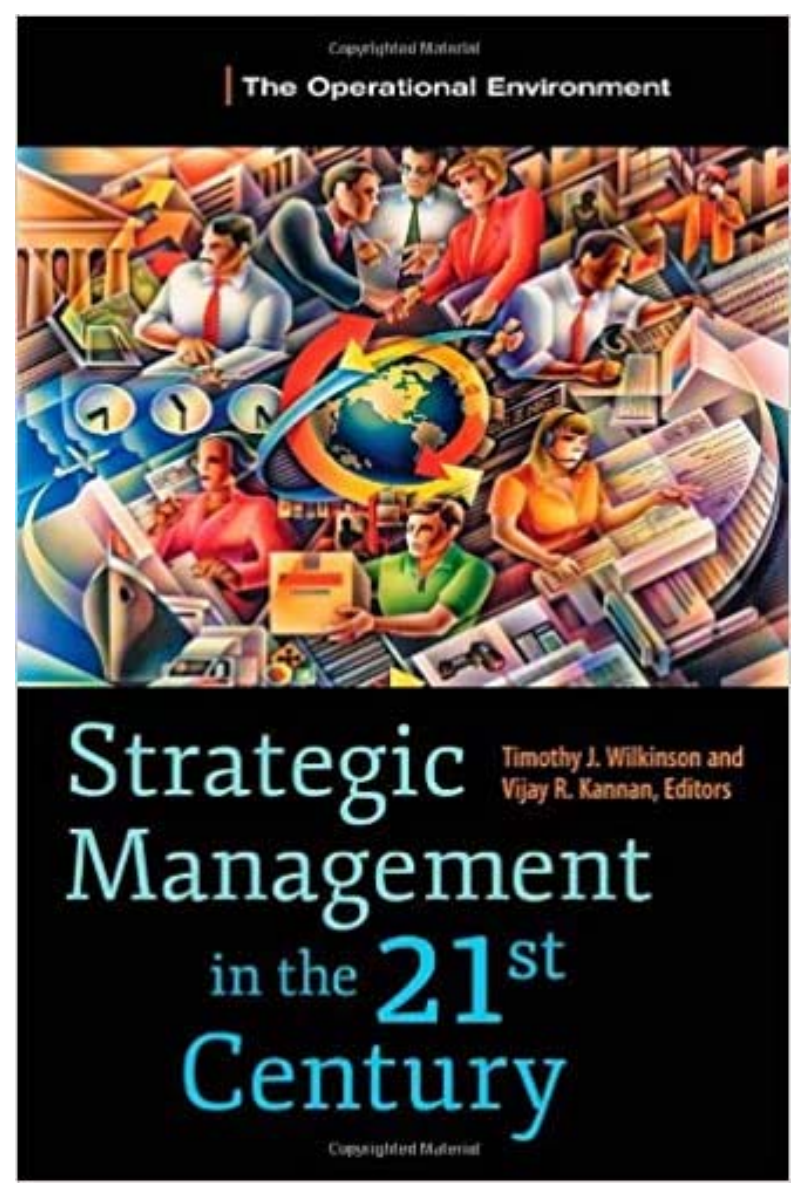

https:// books.google.com/books?id=cdjYAQAAQBAL 
Although the uses and usage of the paper, and its associated concept, scheme and framework, appear to have indicated a validation of the idea, I still have to ask: "Is it now time to remove that question mark?".

It was not obvious for me to make this question. It was due to my lab members, e.g., [2], because their writings seemed to suggest that the question mark of the paper should have been removed.

In fact, some of the most notable achievements of our team have harnessed the power of serendipity in pursuing research, for instance [3- 4].

Nonetheless, to decisively remove the question mark, we will need to perform some earnest study. It is because that removing the question mark will effectively turn the hypothesis into some reliable conclusion. And it would be nice if such a confirmation could arrive ten years after the publication [1].

Now, looking back at the title of this short piece, I cannot refrain from laughing at the question mark (?) right after the word "question mark". It is a question about another 10- year- old question.

\section{References}

[1] Napier NK, Vuong QH. (2013). Serendipity as a strategic advantage?. In: T. Wilkinson (ed.). Strategic Management in the 21st Century (pp. 175- 199). Westport, CT: Praeger/ABC- Clio.

[2] Nguyen MH. (2021). The serendipitous moment leading to the discovery of the Bayesian Mindsponge Framework. OSF Preprints; doi:10.31219/ osf.io/ x5pf4

[3] Vuong QH. (2016). Global mindset as the integration of emerging sociocultural values through mindsponge processes. In: J. Kuada (ed.). Global Mindsets: Exploration and Perspectives (pp. 109- 126). London: Routledge.

[4] Vuong QH. (2021). Western monopoly of climate science is creating an ecodeficit culture. Economy, Land \& Climate Insight. Retrieved from: https:// elc- insight.org/ western- monopoly- of-climate- science- iscreating-an- eco- deficit-culture/ 